\title{
IMMUNE RESPONSES TO ALUM IN THE JAPANESE PUFFERFISH (TAKIFUGU RUBRIPES)
}

\author{
Masahiro Sakai $^{1}$, Takashi Morimoto ${ }^{1}$, Gouranga Biswas $^{2}$, Tomoya Kono $^{1}$, \\ Jun-ichi Hikima ${ }^{1 *}$ \\ ${ }^{1}$ Department of Biochemistry and Applied Biosciences, Faculty of Agriculture, University of \\ Miyazaki, Miyazaki 889-2192, Japan \\ ${ }^{2}$ Kakdwip Research Centre of ICAR-Central Institute of Brackishwater Aquaculture, Kakdwip, \\ West Bengal 743347, India
}

\begin{abstract}
To elucidate the basis of innate immune responses against insoluble compounds (such as silica and alum) through the inflammasome activation pathway in fish, biological assays and expression analysis of immune-related genes were conducted in the Japanese pufferfish (Takifugu rubripes) head kidney (HK) cells. At first, the Japanese pufferfish was stimulated by intraperitoneal injection of alum (4 mg/fish). After $0,6,12,24$ and $48 \mathrm{~h}$ post-injection, HK cells were prepared from the injected fish. To understand functionality of activated inflammatory response, phagocytic activity and superoxide anion production (NBT assay) in the HK cells were assessed. As results, the phagocytic and NBT reduction activities were significantly increased in alum-stimulation. To further clarify the immune response through transcriptomic analysis, expression of 19 cytokine genes was checked by the multiplex reverse transcription (RT)-PCR method. Results showed that expression of IL-6 and type I-IFN genes was significantly elevated in the alum-stimulated fish. Furthermore, expression of NLR-C9 and NLR-C12 genes [i.e., NOD-like receptor (NLR) family genes as sensor molecules of inflammasome], ASC and caspase-1 genes (inflammasome associated molecules) were examined by qPCR. Results indicated an increased expression of four different inflammasome associated genes in the HK cells of fish injected with alum. The results suggested activation of inflammatory response to the alum with a likely involvement of inflammasome components in the Japanese pufferfish.
\end{abstract}

\section{KEYWORDS}

Inflammasome, NLR family genes, cytokine, gene expression, alum, Japanese pufferfish

*Corresponding author. Tel/Fax: +81-985-58-7230.

E-mail address: jhikima@cc.miyazaki-u.ac.jp 